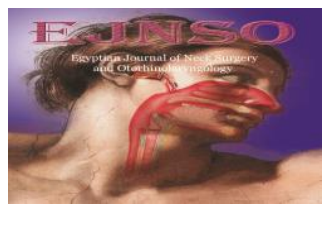

\title{
Safety and Efficacy of Rifampicin in treatment of Rhinoscleroma, Single Institutional Experience on patients over two years period
}

\author{
Asmaa Ahmed Bakhiet ${ }^{1}$, Aly Ragaee Abd Hakeem ${ }^{1}$, Ezzat Mohammed Saleh ${ }^{1}$, Mahmoud \\ Farouk Sherif $^{2}$, Ahmed Hamed Mohammed ${ }^{1}$ \\ 1 Otorhinolaryngology, Faculty of Medicine, Assuit University \\ 2 Pathology, Faculty of Medicine, Assuit University
}

\begin{abstract}
:
Introduction: Rhinoscleroma is a chronic granulomatous infectious disease of the upper respiratory tract. It affects the nose in the majority of patients, but the upper air passages, trachea, and bronchi may also be involved either with or without nasal granuloma.

Objectives: To evaluate the efficacy of Rifampicin $300 \mathrm{mg}$ twice daily for six weeks in treating histologically active rhinoscleroma patients. Evaluation of the drawbacks and side effects of Rifampicin used in the treatment of rhinoscleroma.

Patients and Methods: This prospective randomized descriptive clinical trial was conducted from January 2018 to December 2019 on 20 patients diagnosed clinically and histopathologically as rhinoscleroma scheduled for treatment and received the usual regimen given for free by the Ministry of Health in Egypt; Rifampicin $300 \mathrm{mg}$ twice daily one hour before meals for six months.

Results: The impact of medical treatment with Rifampicin on histopathological examination after treatment showing that only $25 \%$ of cases are cured.

Conclusion: Rifampicin is a less effective and safe drug in the treatment of active rhinoscleroma. Clinical assessment and histopathological examination are nearly correlated and could be used as a parameter in follow-up and assessment.
\end{abstract}

Keywords: Rhinoscleroma, Rifampicin, Antibiotics.

\section{Introduction}

Rhinoscleroma (RS) is a chronic specific granulomatous disease that primarily involves the nose but can affect any part of the respiratory passages. ${ }^{1}$

It is prevalent in Egypt ${ }^{2}$ and other separate areas all around including, India, Central Africa, Central America, Chile, Indonesia, and Middle East countries. ${ }^{3}$

Many patients can't provide the expensive antibiotics to which Klebsiella is sensitive due to their low socioeconomic standard. $^{4}$

If not managed properly, the disease progresses to the final fibrotic phase, where permanent complications due to marked scarring in the tissues leading to nasal deformities, anosmia, and even stridor could happen. ${ }^{5-7}$

The Klebsiella rhinoscleromatis is not susceptible to many antibiotics and, being an intracellular organism, will not be exposed to valuable drug concentrations. A clinical cure is difficult because the end-stage is mucosal fibrosis, which interferes with the respiratory passages' normal function. The fibrosed mucosa also can become secondarily infected with Klebsiella. ${ }^{4}$

To the greatest extent, treatment of rhinoscleroma is medical and depends on the use of antibiotics. By many analysts, surgery should be confined to treating respiratory tract obstruction and residual stenosis. Both 
of these complications may also gain a benefit from laser treatment ${ }^{8}$. $\mathrm{K}$. rhinoscleromatis seem to be sensitive in vitro to many antibiotics. However, according to Ssali, only bactericidal chemotherapeutic agents like streptomycin, ampicillin, and TMP-SMZ ${ }^{8}$ rifampicin have proven to be competent against the disease both systemically nine and local ${ }^{10}$.

Antimicrobial therapy must be offered for long periods from months to years ${ }^{11}$. Clinical improvement is indolent and vague, and recurrence is predictable ${ }^{12}$.

On the ground that $\mathrm{K}$. rhinoscleromatis is an intracellular organism, prolonged courses of Rifampicin would be more convincing due to their high concentration in macrophages. Thus Rifampicin induced encouraging curative results 13,14 . But it should be used for prolonged periods ${ }^{15}$. Rifampicin was presented as a part of multiple therapies for TB in the 1960s, Rifampicin revolutionized treatment and shortened the duration of therapy from 18 to 9 months 16, the optimal dosage of Rifampicin has not been settled. The current recommendation of $10 \mathrm{mg} / \mathrm{kg}$ in guidelines from the WHO has not changed since the introduction of rifampicin ${ }^{17,18}$. rifampicin $600 \mathrm{mg}$ daily for three months used in Egypt as it is available and cheap. ${ }^{19}$

\section{Aim of the work}

\section{This study aimed at:}

- Evaluate the efficacy of Rifampicin $300 \mathrm{mg}$ twice daily for six weeks in treating patients presented with histologically active rhinoscleroma.

- Evaluation of the drawbacks \&side effects of the long course of Rifampicin in the treatment of rhinoscleroma.

\section{Patients and methods}

This prospective randomized descriptive clinical trial was conducted in the otorhinolaryngology department in Assiut University Hospital from January 2018 to December 2019 after obtaining approval from the Medical Ethics Committee, Faculty of Medicine, Assiut University prospectively registered in Clinical Trials. Gov (no: NCT03326050).

\section{Ethical considerations:}

\section{Confidentiality:}

The confidentiality of all contributors included in this study was fully protected possible. The study participants haven't been identified by name in any report or publication resulting from data collected in this study.

\section{Research statement:}

Ethical aspects, whether substantial or procedural, were involved in this research. Before participants were admitted to this study, the purpose and nature of the study, as well as the risks, were explained to them as red discoloration of urine, skin rash, and yellowish discoloration of sclera. All participants agreed that he/she understands the investigational nature of the study, its inherent risks and benefits, his/her rights to terminate participation in this study without affecting his/her rights in having proper health care in the study site, whom to contact with questions regarding the study and that he/she was freely given informed consent to participate in this study.

\section{Informed consent:}

The signed informed consent form was a permanent part of the participant's study records and was maintained in the same manner as other records.

\section{Study design:}

This was a prospective randomized descriptive study conducted on 20 patients diagnosed clinically and histopathologically as rhinoscleroma scheduled for treatment and received the usual regimen given for free by the Ministry of Health in Egypt: 
Rifampicin $300 \mathrm{mg}$ twice daily one hour before meals for six months

\section{Inclusion criteria:}

1. Age above 18 years.

2. Active rhinoscleroma (proved both clinically and histopathologically).

\section{Exclusion criteria:}

1. Patients younger than 18 years old.

2. Inactive rhinoscleroma.

3. Contraindication to treatment, e.g., severe renal or hepatic impairment.

4. Refusal of recruitment in the study by the patient.

5. Known hypersensitivity to the drugs used in the study.

6. Pregnant or lactating woman.

\section{Method:}

Each patient was subjected to the following scheme:

I- History taking:

- Age, gender, educational and economic status.

- Detailed ENT history, including purulent rhinorrhea, postnasal discharge, nasal crustation, hyposmia, and nasal obstruction. Family history, history of any surgery related to the condition, history of any medication related to the condition, history of any chronic disease.

II- Clinical examination:

Detailed general and otorhinolaryngological examination, including endoscopic nasal examination.

II- Diagnostic workup:

Punch biopsy was taken from suspected lesions for histopathological examination pretreatment \& post-treatment using luc's forceps or small punch forceps.

Histopathological examination:

Punch biopsies were immediately fixed in $10 \%$ formalin solution and processed by automated tissue processing till paraffin embedding and then serially cuts into $5 \mathrm{um}$ thick sections on clean glass slides. The slides were stained for microscopic examination.

\section{Clinical Evaluation:}

1. Nasal symptoms: nasal obstruction, crustation, and discharge were compared at the beginning of the treatment \& at the end of the treatment

2. Laryngeal symptoms: dysphonia \&cough were compared pretreatment \&posttreatment in patients who presented by laryngeal affection besides the nasal affection.

3. Laryngoscopic examination in all patients.

4. A liver function test was done for all patients pre \& post-treatment.

Endoscopic examination: using Karl Storz (Germany) endoscope grade 0.

\section{Follow up}

- Patients were asked to come back for clinical Follow up for Evaluation of liver function test and at the end of treatment for biopsy. In each visit, the symptomatic assessment was done. At the end of the endoscopic assessment was done.

- The patients were asked for nasal obstruction, crustation, postnasal discharge, dysphonia, cough,

\section{Statistical analysis:}

Categorical variables were described by number and percent (N, \%), where continuous variables were described by the mean and standard deviation (Mean, SD). Non-parametric Chi-square test was used to compare between categorical variables. A two-tailed $\mathrm{p}<0.05$ was considered statistically convincing. All assays were done by the IBM SPSS 20.0 software.

Results:

Thirty patients diagnosed clinically and histopathologically with rhinoscleroma (figure 1) scheduled for treatment were 
eligible for this study. Eight patients were lost during follow-up, two women get pregnant and were excluded. Finally, twenty patients who were given the usual regimen given for free by the Ministry of Health in Egypt: Rifampicin $300 \mathrm{mg}$ twice daily for six months daily)

\section{Clinical data and observations:} Age and sex incidence:

The age range was from 18 to 50 , with a mean age was $(31,55 \pm 9.54)$. The disease was common in female12 $(60 \%)$ of studied patients were females while males were 8 (40\%). (Table 1, figure 2\&3)

Of interest, about 3 cases (15\%) of studied patients had a positive family history. As regards the economic status of studied patients, there were 2 cases $(10 \%)$ of high educational and economic status.

Table 1 showing age and sex incidence and distribution among patients studied.

\begin{tabular}{|c|c|c|c|}
\hline & \multicolumn{2}{|c|}{$\begin{array}{c}\text { Rifampicin } 300 \\
\text { mg }\end{array}$} & \multirow{2}{*}{$\begin{array}{c}P . \\
\text { value }\end{array}$} \\
\hline & $\begin{array}{c}\text { No. } \\
(n=20)\end{array}$ & $\%$ & \\
\hline \multicolumn{4}{|l|}{ Gender } \\
\hline Male & 8 & 40.0 & \multirow{2}{*}{0.371} \\
\hline Female & 12 & 60.0 & \\
\hline \multicolumn{4}{|l|}{ Age } \\
\hline Range & \multicolumn{2}{|c|}{$18-50$} & \\
\hline Mean \pm SD & \multicolumn{2}{|c|}{$31.55 \pm 9.54$} & \\
\hline
\end{tabular}

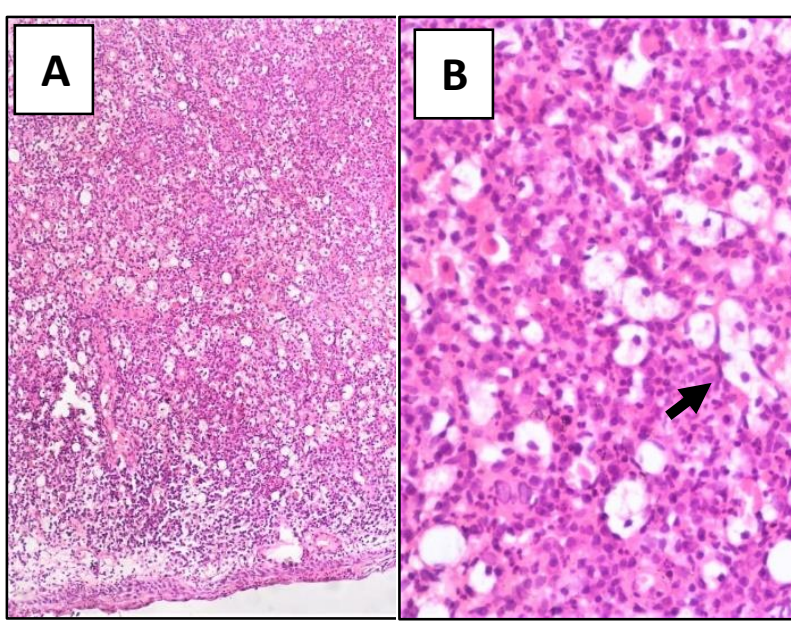

Figure 1: Photomicrographs of sections from a case of active rhinoscleroma. A, a low magnification image showing expansion of the subepithelial tissue by heavy inflammatory reaction covered by intact epithelium (H\&E, 100X). B, a higher magnification image showing the component of inflammatory reaction characteristic of active rhinoscleroma in the form of macrovauolated histiocytes (Mikulicz cells, arrow) on a background of chronic lymphoplasmacytic infiltrate (H\&E, 400X).

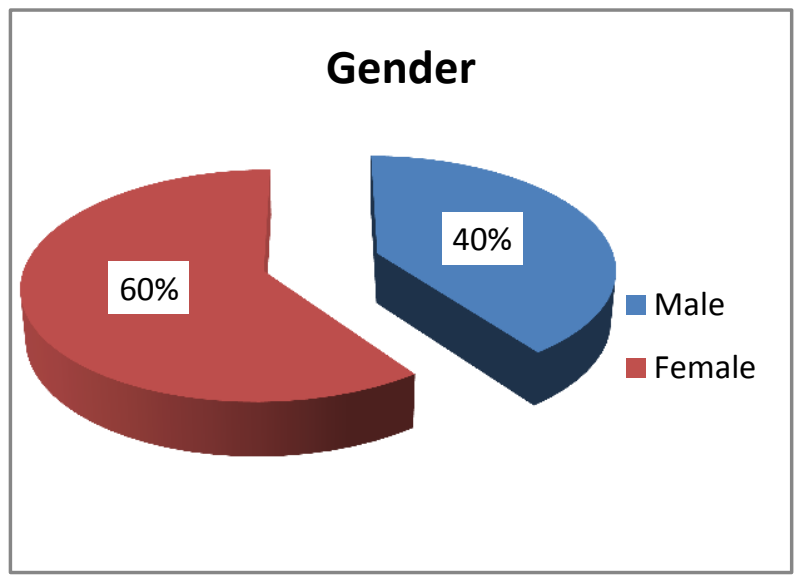

Figure 2: Showing gender distribution. 


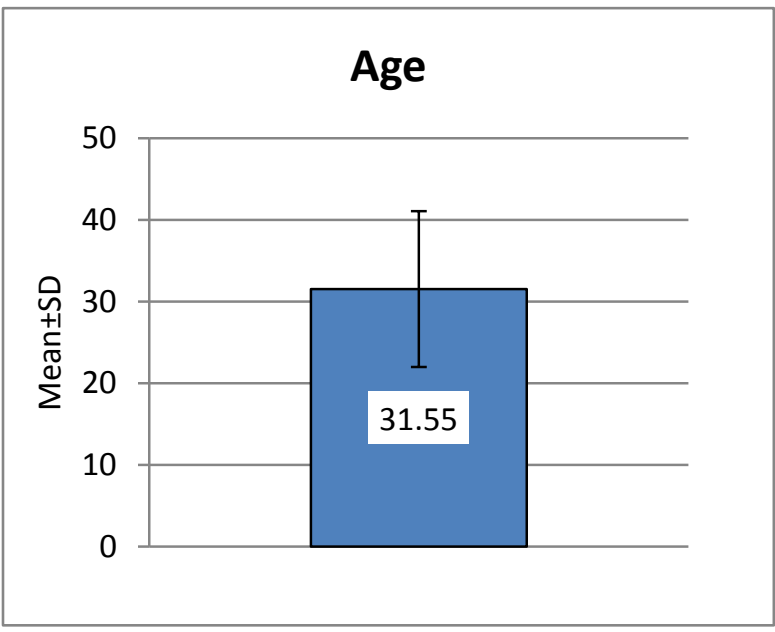

Figure 3: Showing means to age.

\section{Anatomical sites:}

All patients showed the disease in the nose, pharynx, and larynx. The nose was the commonest site of affection accounting for $100 \%$, the next in order was the secondary pharyngolaryngeal affection, accounting 10 $\%$. There was no isolated laryngeal or pharyngeal affection (table 2, figure 4).

Table 2: Showing the incidence of cases according to the site of involvement

\begin{tabular}{|l|c|c|}
\hline \multicolumn{1}{|c|}{ Anatomical sites } & $\begin{array}{c}\text { No. of } \\
\text { cases }\end{array}$ & Percentage \\
\hline Nose alone & 18 & $90 \%$ \\
\hline $\begin{array}{l}\text { Nose \& pharynx \& } \\
\text { larynx }\end{array}$ & 2 & $10 \%$ \\
\hline Pharynx alone & 0 & $0 \%$ \\
\hline Larynx alone & 0 & $0 \%$ \\
\hline
\end{tabular}

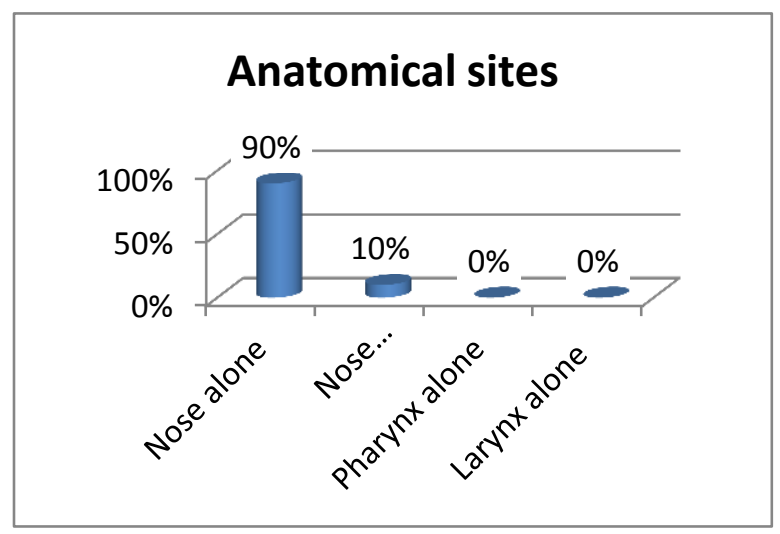

Figure 4: Showing anatomical sites distribution
Symptoms: In all the cases, 20 cases (100\%) complained of bilateral nasal crustation, most of them (18 patients 90\%) complained of bilateral nasal obstruction partial or complete and sometimes nasal \& postnasal discharge in cases where pharynx was involved 2 cases (10\%). There was dryness of the throat and thick postnasal discharge in seven cases. In cases where the larynx was involved 2 cases $(10 \%)$, there was hoarseness of voice which progressed to respiratory obstruction, which necessitated tracheostomy (in both cases). The nasal symptoms were in all cases, bilateral. Besides these symptoms, epiphora was present in one case.

Signs: Bilateral nasal crustation was found in 20 cases $(100 \%)$. Subglottic granulation tissue was found in two cases presented by stridor. Both had a tracheostomy. one case showed extension to the lacrimal passage and obstructed the lacrimal ducts where DCR was planned.

\section{The stage at presentation:}

All the twenty cases presented in the atrophic stage. No case could be detected in the fibrotic (inactive) stage.

All cases $100 \%$ complained of bilateral nasal crustations. After medical treatment, the number of cases who complained of nasal crustations decreased by $40 \%$ (table 3 , figure 5) 
Table 3 showing the incidence of nasal crustation and the impact of treatment on it.

\begin{tabular}{|c|c|c|c|}
\hline \multirow{2}{*}{} & \multicolumn{2}{|c|}{ Rifampicin 300 mg } & \multirow{2}{*}{ P. value } \\
\cline { 2 - 3 } & $\begin{array}{c}\text { No. } \\
(\mathbf{n = 2 0})\end{array}$ & $\%$ & \\
\hline Crustation & & & \\
\hline Pretreatment & 20 & 100.0 & \multirow{2}{*}{0.157} \\
\hline Follow up & 12 & 60.0 & \\
\hline
\end{tabular}

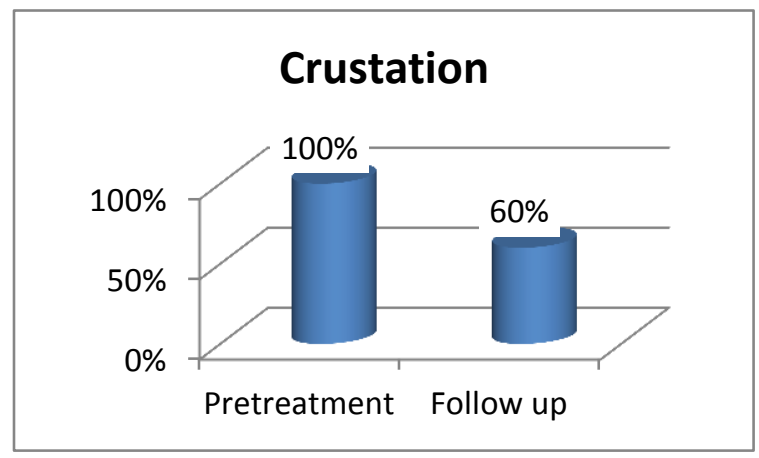

Figure $5 \gg \gg>>$ describe

As regards bilateral nasal obstruction, there were 18 cases $(90 \%)$ presented mainly by nasal obstruction. The number of cases which complaint of nasal obstruction decreased by $55 \%$ in (table 3, figure 5)

Table 4 shows the incidence of nasal obstruction and the impact of medical treatment.

\begin{tabular}{|c|c|c|c|}
\hline \multirow{2}{*}{} & \multicolumn{2}{|c|}{ Rifampicin 300 mg } & \multirow{2}{*}{ P. value } \\
\cline { 2 - 3 } & $\begin{array}{c}\text { No. } \\
(\mathbf{n = 2 0})\end{array}$ & $\boldsymbol{\%}$ & \\
\hline Nasal obstruction & & & \\
\hline Pretreatment & 18 & 90.0 & \multirow{2}{*}{$\mathbf{0 . 0 2 8} *$} \\
\hline Follow up & 7 & 35.0 & \\
\hline
\end{tabular}

\section{Nasal obstruction}

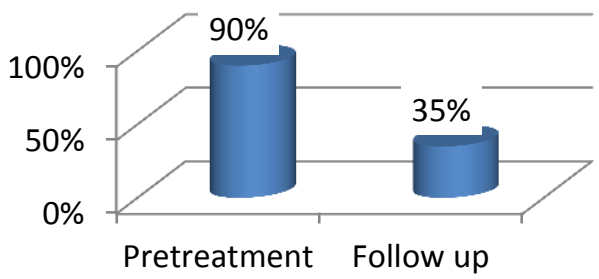

Figure 6 shows the incidence of nasal obstruction and the impact of medical treatment.

As regard nasal discharge, only 2 cases presented by nasal discharge accounting for $10 \%$ of cases. After medical treatment decreased to one case (table 5, figure 6)

Table 5 shows the incidence of nasal discharge and the impact of treatment.

\begin{tabular}{|c|c|c|c|}
\hline \multirow{2}{*}{} & \multicolumn{2}{|c|}{ Rifampicin 300 mg } & \multirow{2}{*}{ P. value } \\
\cline { 2 - 3 } & $\begin{array}{c}\text { No. } \\
(\mathbf{n = 2 0})\end{array}$ & $\%$ & \\
\hline Nasal discharge & & & \\
\hline Pretreatment & 2 & 10.0 & \multirow{2}{*}{0.564} \\
\hline Follow up & 1 & 5.0 & \\
\hline
\end{tabular}

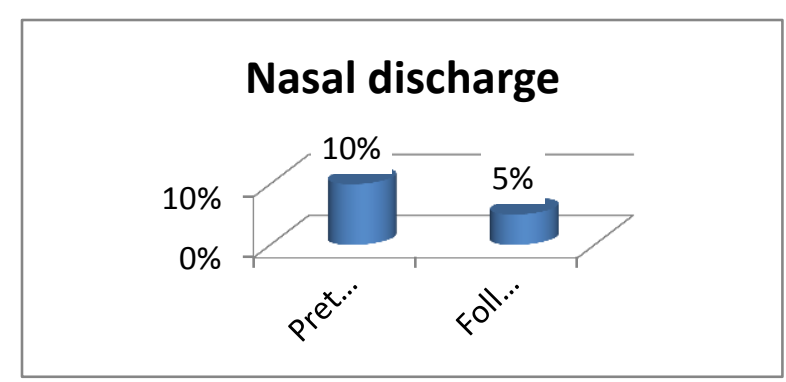

Figure 7 shows the incidence of nasal discharge and the impact of treatment.

Only two cases presented with dysphonia; one of them had partially improved as there was bilateral vocal cord impairment. (Table 6, figure 7) 
Table 6 shows the incidence of dysphonia.

\begin{tabular}{|l|c|c|c|}
\hline \multirow{2}{*}{} & \multicolumn{2}{|c|}{ Rifampicin 300 $\mathbf{~ m g}$} & \multirow{2}{*}{ P. value } \\
\cline { 2 - 3 } & $\begin{array}{c}\text { No. } \\
(\mathbf{n = 2 0})\end{array}$ & $\%$ & \\
\hline Dysphonia & & & \\
\hline Pretreatment & 2 & 10 & \multirow{2}{*}{0.564} \\
\hline Follow up & 1 & 5.0 & \\
\hline
\end{tabular}

As regard histopathological examination after medical treatment, only $25 \%$ of cases cured.

Table 7 shows the impact of medical treatment with Rifampicin on histopathological examination after treatment.

\begin{tabular}{|c|c|c|c|}
\hline \multirow{2}{*}{} & \multicolumn{2}{|c|}{ Rifampicin 300 mg } & \multirow{2}{*}{ P. value } \\
\cline { 2 - 3 } & $\begin{array}{c}\text { No. } \\
(\mathbf{n = 2 0})\end{array}$ & \% & \\
\hline Biopsy & & & \\
\hline Negative & 5 & 25.0 & \multirow{2}{*}{$\mathbf{0 . 0 2 5 *}$} \\
\hline Positive & 15 & 75.0 & \\
\hline
\end{tabular}

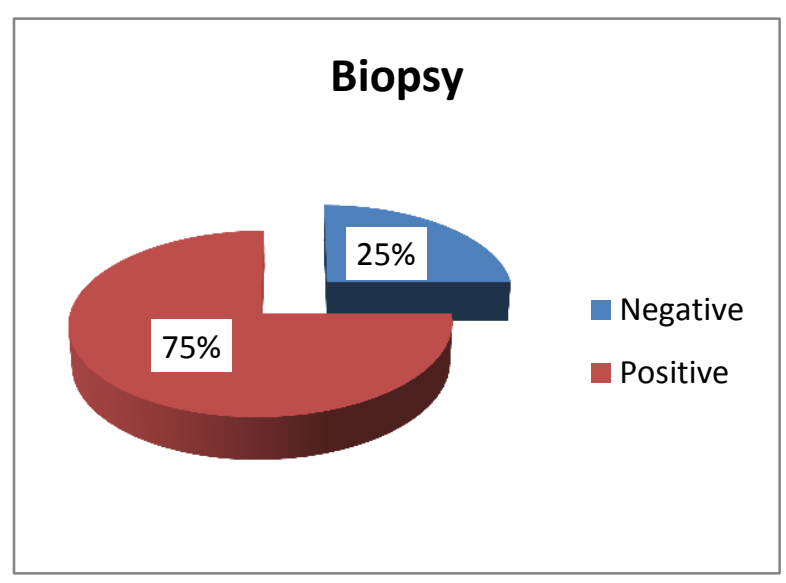

Figure 8 histogram showing the impact of medical treatment with Rifampicin on histopathological examination after treatment.

As regard liver function test, only two cases had elevated liver enzymes post-treatment.
Table 8 shows the impact of medical treatment on liver function test.

\begin{tabular}{|l|c|c|}
\hline \multirow{2}{*}{} & \multicolumn{2}{|c|}{ Group A } \\
\cline { 2 - 3 } & No. (n=20) & \% \\
\hline Liver function test & & \\
\hline Normal & 18 & 90.0 \\
\hline High & 2 & 10.0 \\
\hline
\end{tabular}

\section{Discussion}

RS is very common in Egypt ${ }^{2}$; up till now, it was considered prevailing in some delta regions ${ }^{20}$. We could find a large scale of patients diagnosed with scleroma disease in Upper Egypt in our work. The disease is problematic to patients and specialists. This urged us to carry out the present work; it is clear that extensive work in rhinoscleroma is needed, especially in our country where the disease is common.

Although RS is an endemic disease in Egypt, yet most investigators reported few cases. Botros, Hamilton ${ }^{21}$ reported only 14 cases. Elwi ${ }^{22}$ reported an average of 40 cases Barbary, Fouad ${ }^{23}$ noted 300 patients over many years. Ahmed, El-Badawy ${ }^{2}$ examined 53 cases diagnosed as rhinoscleroma. Abdel-Naby Awad and Hammad ${ }^{24}$ examined 30 patients over 2 years. Fawaz, Tiba ${ }^{6}$ reported 88 cases. Gaafar, Gaafar ${ }^{25}$ included 56 patients in their study. Fattah, Elwany ${ }^{26}$ had 48 cases diagnosed as scleroma were studied over 4 years. All other publications were studying different aspects of the disease by recording a few cases ${ }^{27}$.

Gamea, El Tatawi ${ }^{28}$ reported Only 28 patients in his series over 5 years.

In Upper Egypt, where this work was done in Assiut University Hospital, thirty cases were seen in a relatively short time ( 2 years). This in contradiction to El-Mofty ${ }^{29}$, who assumed that the prevalence was decreasing. 
As compared with what was seen before the Isolated Tracheal and nasopharyngeal scleroma, Bilateral Maxillary swellings, Unilateral nasal mass, diffuse Sino nasal affection with intracranial extension reported by Ahmed, Hassan ${ }^{30}$ tonsillar affection noted by Fattah, Elwany ${ }^{26}$. Lips and gums involvement described by Malkud and Mahajan ${ }^{31}$ oropharyngeal stenosis described by Mukara, Munyarugamba ${ }^{32}$ all these not seen in this current study. This may be attributed to early diagnosis and early treatment in Assiut University Hospital with good diagnostic facilities.

Quevedo ${ }^{33}$ stated that in every country where the disease was endemic, there was a certain locality where the disease was more prevalent, which constituted the nucleus of the area. However, in the present work, most of the patients were noticed to come from rural areas near Assiut provinces, where we couldn't select a special area of endemicity.

The age of patients included in this current study ranged from (18to 50years) with a mean age of $30.98 \pm 9.02$ years. This wide range can be imputed to the very long contact time needed for infection to be presented clinically. In agreement with Fattah, Elwany ${ }^{26}$ who reported forty-eight scleroma patients, their age ranged from (17 to 60 years) with a mean of $39.04+10.5$ years, Ahmed, El-Badawy ${ }^{2}$ in their study found that the patients' age ranged between (12 and 72 years) with a median value of 35 years. Gaafar, Gaafar ${ }^{25}$ found that the ages ranged from (13 to 73 years), and the highest incidence of the disease was in the third and fourth decades of life by (85\%). Pattankar, Roohi ${ }^{34}$ in their study reported that the age range was between (6-80 years) with a mean age of 29.4yrs. Gamea, El Tatawi ${ }^{28}$ reported that Patient age ranged from (16 to 62 years). de Pontual, Ovetchkinen ${ }^{35}$ in their study reported that the median age at diagnosis was 35.7 years. Maguiña, Cortez-Escalante ${ }^{36}$ reported eight cases of Rhinoscleroma from Peru where the age range was (25to 66 years). Fawaz, Tiba ${ }^{6}$ found that the disease usually presents in the second and third decades of life.

In a study done by Zafar, Khan ${ }^{37}$ the peak age of presentation of the disease was in the 4th decade. Ahmed, Hassan ${ }^{30}$ in their study included eleven patients; their age ranged from 33 to 60 years old with a mean of 41years old. Maguiña, Cortez-Escalante ${ }^{36}$. In Peru, noticed that the most common age group of patients was in the 3rd decades (50\%), which correspond to the current study. In another study conducted in the Gulf region by Abalkhail, the median age of the patients was 24 years. ${ }^{38}$. Another study was done by Hart and Rao ${ }^{3}$ also showed a peak incidence in the age group of the 2nd and 3rd decade. ${ }^{3}$. However, Schwartz and Goriniene $^{39}$ diagnosed scleroma in patients aged10-30 years. This narrower range maybe because of the availability of diagnostic facilities aiding early diagnosis and management of patients involved in their study.

There is sex difference in the incidence of RS with female predominance by $60 \%$ of the cases (table 1\&figure 2 ) which coincide with Mukara, Munyarugamba ${ }^{32}$,Hart and Rao ${ }^{3}$., Abalkhail, Satti ${ }^{38}$ showed a female predominance of 1.3:1, and 2.5:1 respectively. Fattah, Elwany ${ }^{26}$ found that there were 20 males and 28 females in his study. Ahmed, Hassan ${ }^{30}$ study included 11 patients; 7 females and only 4males, with a higher prevalence in females. de Pontual, Ovetchkine $^{35}$ found the male: female ratio was 6:5 (54.5\% male). Gamea, El Tatawi ${ }^{28}$ in their study found that there were 13 males $46.5 \%$ and 15 females53.5\%. Gaafar, Gaafar 25 found that There were 26 males $(46.4 \%)$ and 30 females $(53.6 \%)$. Pattankar, Roohi ${ }^{34}$ in their study reported female predominance in $(65.4 \%)$ of the cases. Abdel-Naby Awad and Hammad ${ }^{24}$ in their study foud10 males (33\%) and 20 females (67\%). However, 
Massoud and Awwad ${ }^{40}$ found gender incidence to be equal. Shaw and Martin 41 found sex incidence 4:1 with male preponderance in contradiction to our observation and other workers.

A positive familial history was observed in our series, where 3 cases were presented by positive family history of rhinoscleroma, accounting for $15 \%$ of cases. There was an Italian study that reported 15 cases in one Italian family, and Another American study reported 7 cases in a single American family 42 .

Research published by de Pontual, Ovetchkine ${ }^{35}$ found that 3 out of 11 patients had a positive family history of rhinoscleroma. Gonzales Zamora and Murali ${ }^{43}$ had a case series; his patient had three relatives with a history of rhinoscleroma. Gamea, El Tatawi ${ }^{28}$ found positive family history in 7 cases $25 \%$. Gaafar, Gaafar ${ }^{25}$ reported A positive family history in 9 $(16 \%)$ of their cases. In our study, three affected patients from consanguineous families were significantly younger at presentation than were patients with no family history of RS, which coincides with de Pontual, Ovetchkine ${ }^{35}$.

Although many investigators concluded that the disease was common among the poor natives living under unhygienic conditions and low socioeconomic standard Botros, Hamilton 21, Yasin and Safwat ${ }^{44}$, Ahmed, El-Badawy ${ }^{2}$, Gaafar, Gaafar ${ }^{25}$, yet $10 \%$ of our cases were found educated with good sanitation and this agrees with Quevedo ${ }^{33}$ observation.

Of the 20 RS cases studied $100 \%$ was detected in the nose with secondary involvement of the pharynx and larynx in 2 cases $10 \%$ (table 2). This coincides with Quevedo ${ }^{33}$, Yasin and $\mathrm{Safwat}^{44}$, Sinha, Pandhi ${ }^{45}$ who reported $100 \%$ affection for the nose. Abalkhail found that the nose was involved in $100 \%$ of cases ${ }^{38}$. Pattankar, Roohi ${ }^{34}$ reported nasal affection in all the cases. de Pontual, Ovetchkine ${ }^{35}$ found (10 of 11 patients) presented with nasal involvement with scleroma. Schwartz and Goriniene 39 also documented nasal involvement in $100 \%$ of cases. Fawaz, Tiba 6 noticed nasal involvement occurred in $100 \%$ of their patients. Gamea, El Tatawi ${ }^{28}$ found that the nose was affected in all 28 cases $100 \%$ Gaafar, Gaafar ${ }^{25}$ reported that the nose was affected in all the patients included (56 cases, 100\%) in their study.

As regard laryngeal affection Abalkhail, Satti ${ }^{38}$ found that 11 cases out of 25 cases showed laryngeal involvement, de Pontual, Ovetchkine ${ }^{35}$ found 1 patient presented with laryngeal invasion. Pai and Bhat ${ }^{46}$ found laryngeal affection in two patients (7\%), which coincide with the current study in which only 2 cases (10\%) had laryngeal involvement, which coincides with a study done by Schwartz and Goriniene ${ }^{39}$, who found rhinopharyngolaryngeal involvement occurred in $8 \%$ of cases. Ahmed, El-Badawy 2 in their study, found that combined nasal affection with other regional involvement was most frequently encountered with the larynx in $65 \%$ of his cases. Comparing these studies, laryngeal involvement in our current study was less and may be due to early presentation of the patients to the hospital and early diagnosis and start of adequate treatment.

As regard nasopharynx affection no cases of nasopharynx could be detected; this coincides with Abalkhail, Satti 38, who found that the nasopharynx was involved in 6 cases only out of 25. Pai and Bhat 46 reported nasopharyngeal involvement in four cases only out of 28. Ahmed, ElBadawy ${ }^{2}$ found that the nasopharynx was affected in 13 patients out of 56 patients $(23 \%)$. Schwartz and Goriniene 39 nasopharyngeal involvement occurred in $18 \%-43 \%$ The low incidence of nasopharyngeal involvement in this series is probably due to the difficulty of direct 
Visualization as the nasal cavities were usually blocked by crusts.

The observation of most investigators is that the common primary site of RS is in the nose and the pharynx, and the larynx affection is often secondary infiltration from the nasal site. In many cases, the nasal affection is mainly anterior, where the posterior part of the nose, the nasopharynx was found to be free of any infiltrate. Mani, Bapuraj ${ }^{47}$ found a case report of isolated laryngeal scleroma. Elwi ${ }^{22}$ found only 3 cases of isolated laryngeal scleroma all over a period of 25 years. None of the cases of our study has revealed affection of the trachea, middle ear, cervical lymph glands, orbit, and brain it may be noticed that some investigators documented extension of RS to the trachea (Bigi, Bartolomeo ${ }^{48}$, Yigla, BenIzhak ${ }^{49}$, Umphress and Raparia ${ }^{50}$, Mukara, Munyarugamba ${ }^{32}$, Verma, Kanawaty ${ }^{51}$, Maguiña, Cortez-Escalante ${ }^{36}$ ) middle ear (Malkud and Mahajan ${ }^{31}$, Maguiña, CortezEscalante $^{36}$, Ali, Natu ${ }^{52}$, Kakeri and Patel ${ }^{53}$, Barbary, Fouad ${ }^{23}$ ) cervical lymph nodes Gaafar, Gaafar 25, Akhtar, McArthur 54, Gadomski $^{55}$ ).

In our study, all patients presented nasal crustation, which disagrees with Fawaz, Tiba ${ }^{6}$ found that crustation in $46 \%$ of his cases.

The second most common complaint was nasal obstruction by $90 \%$ of our cases Fawaz, Tiba ${ }^{6}$ found that $100 \%$ of their cases were presented by nasal obstruction. All our patients presented with bilateral nasal affection, which may be asymmetric; this result coincides with previous reports Fawaz, Tiba ${ }^{6}$, Schwartz and Goriniene ${ }^{39}$. Absolute unilateral affection isn't seen.

Dysphonia was found in only 2 cases; both had stridor \& and had a tracheostomy, de Pontual, Ovetchkine ${ }^{35}$ found only 1 case of laryngeal affection.

\section{Surgical treatment:}

A variety of surgical procedures were performed on our patients. Tracheostomy was performed for two patients with laryngeal or upper tracheal obstruction. one case was planned for dacryocystorhinostomy.

\section{Medical treatment:}

Antimicrobial chemotherapy has been tried obviously against scleroma. Clinical cures can be obtained with various chemotherapeutic agents but relapse is high 56 . So vigorous therapy must be carried out 57. Antibiotics are the gold standard treatment of rhinoscleroma 5 . Systemic streptomycin ${ }^{58}$ was the first drug to be used successfully, and for years it was the main drug against rhinoscleroma, but it has many drawbacks, especially in the vestibular system, and it has now acquired resistance. Tetracycline is a historical agent due to its low cost and efficacy ${ }^{59}$ ). Tetracycline is to be avoided in the pediatric age group and during pregnancy because of teeth staining 60

Cephalosporin is effective in vitro, but recurrence may occur on the stoppage of treatment ${ }^{61}$. Rifampicin is one of the most potent chemotherapeutic agents 62 Rifampicin has been used systemically with good results in the treatment of scleroma. But patients receiving this drug should be strictly checked for signs of toxicity ${ }^{63}$.

Although Ciprofloxacin is an expensive agent, it has good compliance and competence ${ }^{64}$.

Antimicrobial chemotherapy must be sustained for prolonged periods (3 to 6 months) until the histopathological examination is negative ${ }^{49}$.

In this study, we used Rifampicin as a drug of treatment; only $25 \%$ of the cases were cured histopathologically, and that coincides with Bhargava and Date ${ }^{65}$, who reported no response to Rifampicin $450 \mathrm{mg}$ daily for four months. However, in clinical 
assessment follow up nasal obstruction decreased by $55 \%$ of cases, and nasal crustation decreased by $40 \%$ of cases another regimen of 6months of treatment was continued for those who experienced clinical improvement despite positive biopsy. Also, in the liver function test posttreatment, 2 cases developed raised liver enzymes which returned to normal one month later. This low cure rate is in contrast to Gamea and El-Tatawi ${ }^{15}$ in; their study on 15 patients treated with Rifampicin systemically showed that Rifampicin is efficient in the treatment of rhinoscleroma. A probable explanation of this low cure rate could be drug resistance or patient noncompliance.

Despite the improvement of nasal obstruction and nasal crustation by $55 \%, 40 \%$, respectively, the free histopathological examination in the group was documented only in $25 \%$ of cases.

\section{Summary}

This is a prospective randomized descriptive study conducted in the Otolaryngology Department, Assiut University Hospital, from January 2018 to December 2019 after obtaining approval from the Medical Ethics Committee, Faculty of Medicine, Assiut University and was prospectively registered in Clinical Trials.gov (no: NCT03326050). This study was conducted on 20 patients diagnosed clinically and histopathologically as rhinoscleroma scheduled for treatment (twenty patients who were given the usual regimen given for free by the Ministry of Health in Egypt; Rifampicin 300 mg twice daily for six months daily)

There were $60 \%$ of studied patients were females while males were $40 \%$. The age of patients included in this current study ranged from (18to 50years) with a mean age of $31.55 \pm 9.54$ years.
Histopathological examination: Punch biopsy was taken after the end of treatment.

\section{Clinical Evaluation:}

1. Nasal symptoms: nasal obstruction, crustation, and discharge were compared at the beginning of the treatment \& at the end of the treatment.

2. Laryngeal symptoms: dysphonia \&cough were compared pretreatment \&posttreatment in patients who presented by laryngeal affection besides the nasal affection.

3. Laryngoscopic examination in all patients.

4. A liver function test was done for all patients pre \& post-treatment.

Endoscopic examination: using Karl Storz (Germany) endoscope grade 0.

\section{Follow up}

- Patients were asked to come back for clinical Follow up at four weeks for Evaluation of liver function test and at the end of treatment for biopsy. In each visit, the symptomatic assessment was done. At the end of treatment, an endoscopic assessment was done.

- The patients were asked for nasal obstruction, crustation, postnasal discharge, dysphonia, cough,

\section{Conclusion:}

Rifampicin is a less effective and safe drug in the treatment of active rhinoscleroma. Clinical assessment and histopathological examination are nearly correlated and could be used as a parameter in follow-up and assessment.

\section{Recommendations}

- Close follow-ups are needed to detect future recurrences, and Long-term follow-up is required to monitor for re-activation of disease after treatment.

- There is growing evidence that Rifampicin is not an appropriate 
antimicrobial agent and possibly lengthens the duration of therapy.

- Further investigation of the use of other antibiotic agents to treat rhinoscleroma, including comparative trials with other therapies, would b of considerable interest.

- Further studies of the sex predominance, family history, economic and educational status on larger scales should be recommended.

\section{References:}

1.Miller AH. Scleroma of the larynx, trachea and bronchi. The Laryngoscope. 1949;59(5):506-14.

2.Ahmed AR, El-Badawy ZH, Mohamed IR, Abdelhameed WA. Rhinoscleroma: a detailed histopathological diagnostic insight. Int J Clin Exp Pathol. 2015;8(7):8438-45.

3.Hart CA, Rao SK. Rhinoscleroma. J Med Microbiol. 2000;49(5):395-6.

4.Borgstein J, Sada E, Cortes R. Ciprofloxacin for rhinoscleroma and ozena. Lancet. 1993;342(8863):122-4.

5.Bailhache A, Dehesdin D, François A, Marie J-P, Choussy O. Rhinoscleroma of the sinuses. Rhinology. 2008;46(4):338-41.

6.Fawaz S, Tiba M, Salman M, Othman H. Clinical, radiological and pathological study of 88 cases of typical and complicated scleroma. The clinical respiratory journal. 2011;5(2):112-21.

7.Zhong Q, Guo W, Chen X, Ni X, Fang J, Huang $Z$, et al. Rhinoscleroma: a retrospective study of pathologic and clinical features. J Otolaryngol Head Neck Surg. 2011;40(2):167-74.

8.William I. Tracheal rhinoscleroma treated by argon laser. Thorax. 1982;37(9):638-9.

9.Goihman-Yahr M. Rhinoscleroma and rhinosporidiosis: an approach through history. International journal of dermatology. 1986;25(7):476-8.

10.Gamea A. Local Rifampicin in treatment of rhinoscleroma. The Journal of Laryngology \& Otology. 1988;102(4):31921.
11.Lenis A, Ruff T, Diaz J, Ghandour E. Rhinoscleroma. Southern medical journal. 1988;81(12):1580-2.

12.Paul C, Pialoux G, Dupont B, Fleury J, Gonzalez-Canali G, Eliaszewicz M, et al. Infection due to Klebsiella rhinoscleromatis in two patients infected with human immunodeficiency virus. Clinical infectious diseases. 1993;16(3):441-2.

13.Keschner D, Kelley TF, Wong BJ. Transglottic scleroma. American journal of otolaryngology. 1998;19(6):407-11. 14.Villar MD, Vallejos MP, Arregui R, Vega C, Medina D. Rinoescleroma, una enfermedad rara en Chile: Reporte de un caso clínico. Rev otorrinolaringol cir cabeza cuello. 2004;15(2):127-33.

15.Gamea A, El-Tatawi F. The effect of Rifampicin on rhinoscieroma: an electron microscopic study. The Journal of Laryngology \& Otology. 1990;104(10):7727.

16.Zumla A, Nahid P, Cole ST. Advances in the development of new tuberculosis drugs and treatment regimens. Nature reviews Drug discovery. 2013;12(5):388-404.

17.Hofman S, Segers M, Ghimire S, Bolhuis M, Sturkenboom M, Van Soolingen D, et al. Emerging drugs and alternative possibilities in the treatment of tuberculosis. Expert Opinion on Emerging Drugs. 2016;21(1):103-16.

18.van Ingen J, Aarnoutse RE, Donald PR, Diacon AH, Dawson R, Plemper van Balen $\mathrm{G}$, et al. Why do we use $600 \mathrm{mg}$ of Rifampicin in tuberculosis treatment? Clinical Infectious Diseases. 2011;52(9):e194-e9.

19.Nassim NT. Endoscopic-assisted laser therapy for extensive rhinoscleroma. The Egyptian Journal of Otolaryngology. 2012;28(2):89-92.

20.Taha A, Fatt-hi A, Kadir MA. Surgical management of cicatricial post-scleromatous sub-glottic stenosis. The Journal of Laryngology \& Otology. 1981;95(8):827-33. 21.Botros G, Hamilton PK, Floyd TM, Mufti A, Imam A. LXXVII Scleroma in Egypt. Annals of Otology, Rhinology \& Laryngology. 1954;63(4):1031-55. 
22.Elwi AM. Some clinicopathological observations on scleroma. The Journal of Laryngology \& Otology. 1958;72(1):32-47. 23.Barbary A, Fouad H, Fatt-Hi A. Scleroma affecting the middle ear cavity with report of three cases. Annals of Otology, Rhinology \& Laryngology. 1974;83(1):107-10.

24.Abdel-Naby Awad OG, Hammad MS. Topical mitomycin $\mathrm{C}$ as an adjunct to surgical debulking and medical treatment in rhinoscleroma. American journal of rhinology \& allergy. 2015;29(4):e95-e9.

25.Gaafar HA, Gaafar AH, Nour YA. Rhinoscleroma: an updated experience through the last 10 years. Acta Otolaryngol. 2011;131(4):440-6.

26.Fattah HMA, Elwany S, Mandour Z. Scleroma: New patterns and approaches to an old disease. Egyptian Journal of Ear, Nose, Throat and Allied Sciences. 2011;12(3):1339.

27.Attia O. Rhinoscleroma and malignancy: two cases of rhinoscleroma associated with carcinoma. The Journal of Laryngology \& Otology. 1958;72(5):412-5.

28.Gamea A, El Tatawi F, Gamea M. Changes in the pattern of rhinoscleroma in Egypt: updated experience. The Journal of Laryngology \& Otology. 2019;133(10):87983.

29.El-Mofty A. XXXII Histological Examination of Scleroma. Annals of Otology, Rhinology \& Laryngology. 1962;71(2):377-81.

30.Ahmed MAH, Hassan OM, El Batawi AM. Our Experience with Rhinolaryngoscleroma \& its atypical presentations in Egypt. Pan Arab Journal of Rhinology. 2019;9(3):2-7.

31.Malkud S, Mahajan P. Rhinoscleroma: An unusual presentation. Indian dermatology online journal. 2018;9(3):191-5.

32.Mukara B, Munyarugamba P, Dazert S, Löhler J. Rhinoscleroma: a case series report and review of the literature. European Archives of Oto-Rhino-Laryngology. 2014;271(7):1851-6.

33.Quevedo J. LIX Scleroma in Guatemala: With a Study of the Disease Based on the Experience of 108 Cases. Annals of Otology,
Rhinology \& Laryngology. 1949;58(3):61345.

34.Pattankar VL, Roohi S, Reddy BN. Clinicopathological study of Rhinoscleroma with Mast cell profile. International Journal of Scientific and Research Publications. 2013;3(1):1-5.

35.de Pontual L, Ovetchkine P, Rodriguez D, Grant A, Puel A, Bustamante $J$, et al. Rhinoscleroma: a French national retrospective study of epidemiological and clinical features. Clin Infect Dis. 2008;47(11):1396-402.

36.Maguiña C, Cortez-Escalante J, OsoresPlenge F, Centeno J, Guerra H, Montoya M, et al. Rhinoscleroma: eight Peruvian cases. Revista do Instituto de Medicina Tropical de São Paulo. 2006;48(5):295-9.

37.Zafar U, Khan N, Afroz N, Hasan S. Clinicopathological study of non-neoplastic lesions of nasal cavity and paranasal sinuses. Indian journal of pathology and microbiology. 2008;51(1):26-8.

38.Abalkhail A, Satti M, Uthman M, Al Hilli F, Darwish A, Satir A. Rhinoscleroma: a clinicopathological study from the Gulf region. Singapore medical journal. 2007;48(2):148-51.

39.Schwartz R, Goriniene ER. Emerging drugs and alternative possibilities in the treatment of tuberculosis. Medscape. 2008;6(2):64-9.

40.Massoud G, Awwad H. Scleroma of the upper air-passages: A clinico-radiological study of 84 cases. Journal of the Faculty of Radiologists. 1959;10(1):44-8.

41. Shaw H, Martin H. Rhinoscleroma-a clinical perspective. The Journal of Laryngology \& Otology. 1961;75(12):101139.

42.Chatterji P, Verma S, Mathur J. Scleroma of the antrum and ethmoid. The Journal of Laryngology \& Otology. 1969;83(9):917-23. 43.Gonzales Zamora J, Murali AR. Rhinoscleroma with Pharyngolaryngeal Involvement Caused by Klebsiella ozaenae. Case Rep Infect Dis. 2016;16(4):6536275.

44.Yasin A, Safwat F. Unusual features of scleroma. Journal of Laryngology and Otology. 1966;80(1):524-32. 
45.Sinha A, Pandhi S, Prakash O. Aetiopathogenesis of scleroma. The Journal of Laryngology \& Otology. 1969;83(2):1339.

46.Pai S, Bhat V. Rhinoscleroma -A Clinical Study and Review of Literature. Medscape. 2015;3(1):595-601.

47.Mani N, Bapuraj J, Nehru V, Badotra B, Suri S. Solitary scleroma of larynx-unusual computed tomography findings: A case report. Indian Journal of Radiology and Imaging. 2002;12(1):95-100.

48.Bigi A, Bartolomeo M, Costes V, Makeieff M. Tracheal rhinoscleroma. European annals of otorhinolaryngology, head and neck diseases. 2016;133(1):51-3.

49. Yigla M, Ben-Izhak O, Oren I, Hashman N, Lejbkowicz F. Laryngotracheobronchial involvement in a patient with nonendemic rhinoscleroma. Chest. 2000;117(6):1795-8.

50.Umphress B, Raparia K. Rhinoscleroma. Arch Pathol Lab Med. 2018;142(12):1533-6.

51.Verma G, Kanawaty D, Hyland R. Rhinoscleroma causing upper airway obstruction. Canadian respiratory journal. 2005;12(1):43-5.

52.Ali I, Natu SS, Singh S, Parveen G, Dubey M. Rhinoscleroma: A Case Report with Review of Literature. Arch CranOroFac Sc. 2014;3(1):1-7.

53.Kakeri A, Patel A. A rare case of primary otoscleroma of the middle ear. The Journal of Laryngology \& Otology. 2012;126(12):12767.

54.Akhtar M, McArthur PD, Alt MA. Rhinoscleroma. Ultrastructural Study of a Case Before and After Treatment. Annals of Saudi Medicine. 1982;2(1):23-9.

55.Gadomski CF. Rhinoscleroma: Report of a Case. Archives of Otolaryngology. 1939;29(4):681-94.

56.Ssali C. The management of rhinoscleroma. The Journal of Laryngology \& Otology. 1975;89(1):91-9.

57.Ammar ME-SM, Rosen A. Rhinoscleroma mimicking nasal polyposis. Annals of Otology, Rhinology \& Laryngology. 2001;110(3):290-2.

58.Russell DA, Moore JM, Mattman LH. Rhinoscleroma Successfully Treated with
Streptomycin. Journal of the American Medical Association. 1952;148(8):642-3.

59.Perkins B, Hamill R, Musher D, O'hara C. In vitro activities of streptomycin and 11 oral antimicrobial agents against clinical isolates of Klebsiella rhinoscleromatis. Antimicrobial agents and chemotherapy. 1992;36(8):17857.

60.Shum TK, Whitaker CW, Meyer PR. Clinical update on rhinoscleroma. The Laryngoscope. 1982;92(10):1149-53.

61.Trautmann M, Held T, Ruhnke M, Schnoy N. A case of rhinoscleroma cured with ciprofloxacin. Infection. 1993;21(6):403-6.

62.Morris AB, Brown RB, Sands M. Use of rifampin in nonstaphylococcal, nonmycobacterial disease. Antimicrobial agents and chemotherapy. 1993;37(1):1-7.

63.Riad G. Comparative study of the effects of Rifampicin, tetracycline and combined rifampicin with tetracycline on rhinoscleroma. Thesis, Tanta University, Egypt. 1982:51-9.

64.Avery RK, Salman SD, Baker AS. Rhinoscleroma treated with ciprofloxacin: a case report. The Laryngoscope. 1995;105(8):854-6.

65.Bhargava D, Date A. Palatal presentation of scleroma. The Journal of Laryngology \& Otology. 2001;115(8):679-80. 